The Journal of Animal \& Plant Sciences, 30(3): 2020, Page: 685-692

ISSN (print): 1018-7081; ISSN (online): 2309-8694

\title{
A NEW SPECIES OF GENUS AGROTIS OCHSENHEIMER (LEPIDOPTERA: NOCTUIDAE) IN PAKISTAN
}

\author{
M. Sajjad ${ }^{1}$, Z. M. Sarwar*1, M. Binyameen ${ }^{1}$, M. Qasim² and M. H. Bashir ${ }^{3}$ \\ ${ }^{1}$ Department of Entomology, FAST Bahauddin Zakariya University Multan; ${ }^{2}$ Department of Entomology, Faculty of \\ Agriculture, The University of Poonch, Rawalakot, Azad Jammu and Kashmir, Pakistan \\ ${ }^{3}$ Department of Entomology, Agriculture University Faisalabad \\ ${ }^{*}$ Corresponding author's email: zmsarwar@bzu.edu.pk
}

\begin{abstract}
The family Noctuidae has most important insect pests which damage the cereal and cash crops. For proper identification and classification of these insect pests, taxonomy plays a vital role form successful management strategy. In the present study, several diagnostic characteristics were examined but typically concentration was made on genitalia for the proper identification of species. Specimens were dissected carefully and genitalia were examined under Stereo microscope. As a result, Agrotis hirsutumus is new to science and the first time described from Pakistan. Agrotis species which have been reported from Pakistan are also included in the key.
\end{abstract}

Keywords: Agrotis: hirsutumu, Bahawalpur, Male Genitalia, Systematic Study, Pakistan. https://doi.org/10.36899/JAPS.2020.3.0081

Published online March 25, 2020

\section{INTRODUCTION}

Lepidoptera is one of the most predominant terrestrial order and perform critical role in an ecosystem including nutrient cycling, decomposition, pollination and providing prey for passerine birds (Schmidt and Roland 2006; Jaroensutasinee et al., 2011). This group is most suitable to quantify the evaluations between the insect faunas especially for their species richness and evenness in response to flora and climate (Nielsen and Common 1991). This order comprises of butterflies and moths that have 160000 described species belonging to 180 families (Van Nieukerken et al., 2011; Rabieh 2018). From these families, Noctuidae is probably the most dominating macro-lepidopteran family with more than 35000 described species belonging to 4200 genera and 29 subfamilies (Meena et al., 2017). Noctuid moths are considered most dynamic component of natural and agricultural ecosystems. Most of the pest species have posed threat to the agricultural crops and forests due to their high species biodiversity, maximum reproductive rate, migratory and phytophagous feeding nature of the larvae. The crucial feeding behavior of immatures gives the damaging pest status to the members of family Noctuidae in agro-ecosystem worldwide. Subfamily Noctuidae also economically very important tribes, Agrotini and noctuini (Pogue 2006).

A systematic study of the genus Agrotis is very important for boosting the crop yield because members of this genus are the cutworms which are roots and foliage feeders of many economic crops such as cotton, wheat, rice, sugarcane, sunflower, and farm vegetables like ladyfinger, cabbage, potato, tomato and tobacco
(Kravchenko et al., 2006). Most of the caterpillars live inside the cracks and crevices of soil during daylight hours but vigorously damage the leaves at night with high reproductive rate (Gillott 2003. For proper identification and classification of these species, genital organs are most frequently used because their genital organs are structurally species specific. Sometimes, species of the genus are morphologically similar but differ on the base of genital organs (Atay 2012). Genus Agrotis was first time described by (Ochsenheimer 1816) and added 46 species. Among these species, three species were new identified and 43 species have been already described but associated with other genera. Agrotis species were regrouped into other genera by (Hübner 1821). (Curtis 1827) identified Agrotis segetum Denis \& Schiffermüller as the type species and also mentions the problems associated with the characterization for grouping of variable species and make three species groups on the basis of male antenna. (Smith 1890) was first time suggested that the characteristics of the genitalia play most vital role in the identification of Agrotis species because morphological characters are misleading and also mention that the previous efforts have been poor and arbitrary. (Hampson 1894) exclusively used the morphological characters including spines on tibia and type of male antenna. Later on, Hampson continues his work till 1920 and classified several Agrotis species associated with different genera and this classification system was followed for a century. (Kitching 1984) and (Lafontaine 2004) improved the classification of Hampson on the basis of genital characters and also taking a major step toward the current classification through rearrangement of the subfamilies, genera and 
reevaluates species status.( Lafontaine 2004) revised the taxonomic status of Agrotini from North American and diagnosis the genus Agrotis through morphology and genitalic characteristics of both sexes.( Naz 2011) reported nine species from Pakistan and (Sekhon 2015) re-described four species on the base of genitalia; Agrotis flammeta Schiff, A. segetum Schiff, A. ypsilon Potenberg and A. biconica Kollar from India of the genus Agrotis.

For considering the significance of taxonomy and biodiversity, the current research was conducted to identify and classify the species of subfamily Noctuinae by morphological and genital characteristics of the genus Agrotis from district Bahawalpur, Punjab, Pakistan.

\section{MATERIALS AND METHODS}

Field collection of Noctuid moth: Moths belonging to the subfamily Noctuinae were collected by the conical iron light traps with bulb (200 watts) from different localities of the District Bahawalpur, during 2017-18. The selected localities (town level) of Bahawalpur were; Lal Suhanra National Park, Dera Bakha, Chak No. 7BC, Yazman, and Khanqah Sharif.

Examination of genitalia: Noctuid moths were killed in potassium cyanide jar. Then these killed moths were soaked in butter paper for 2 to 3 hours in glass petri dishes to soften the body appendages such as wings, antenna and legs for proper spreading. A comprehensive picture of adult along with tag was taken by digital camera (HD $1500 \mathrm{~T}$ Meiji). Both forewings and hind wings were detached from the body by giving gentle upward jerk to examine the venation. These wings were descaled by immersing into $70 \%$ alcohol for about 1 to 2 minutes and then transferred into sodium hypochlorite $(\mathrm{NaOCl})$ solution for 20 minutes and washed 2 to 3 times by distal water. To study the genitalia, moth abdomen was cut from the body with the help of forceps and scissor and dipped for overnight in 10\% potassium hydroxide $(\mathrm{KOH})$ solution to relax the internal muscles. Insect abdomen was carefully dissected by sharp and fine needles under the stereomicroscope (Meiji EMZ-5TR). Genitalia was washed 2 to 3 times in distilled water to wash out the $\mathrm{KOH}$ residues and subsequently dipped for 15 to 20 minutes into $50 \%, 60 \%$, and $70 \%$ concentration of ethanol to clean all the parts of genitalia (Triplehorn and Johnson, 2005). Photography/illustration of the diagnostic characteristics of the adult moth and genitalia were taken by a digital camera (HD 1500 T Meiji).

Permanent mounting of the genitalia: Canada balsam was used for permanent mounting of genitalia and wings on glass slides along with appropriate labeling. Slides were left in horizontal positions for 3 to 4 days for drying and then shifted into slide boxes.

\section{RESULTS AND DISCUSSION}

\section{Genus Agrotis Oohsenheimer, 1816}

Diagnostic characteristics: Adult of the genus Agrotis has a muscular proboscis with strong oblique labial palpi with scales and second segment is intensively projected in front. Frons is rounded, sometimes with small and dissimilar prominence. Agrotis species have smooth, naked and without lashes eyes. In male moth, half of the antenna is bipectinate and remaining half is ciliated. A tuft of hairs is present on thorax and abdomen. Forewings are non-crenulated at outer margin, while hind wings have 3 or 4 veins from the cell. Tibiae fringed with different length of spines in different genera. Spines present on all tibiae, sometimes absent in one or two tibias but in few case spines absents in all tibia. Valva of the male genitalia is slender and sides are broad, attached with corona and clasper; clavus is hairy. Vesica of the aedeagus is unarmed or with one or two scobinate blotches.

Keys to species of the genus Agrotis Ochsenheimer from Pakistan: In male genitalia, aedeagus is highly sclerotized, cylinder-like with coiled and membranous vesica ......................................2

Aedeagus of the male genitalia is long, well developed while vesica nearly 2 to 6 time as long as aedeagus......................................22

1. Uncus very long in length, slender form and well-developedscaphium found at tuba analis......... A. cinerea (Denis and Schiffermüller)

- Uncus moderate in length curved at the tip that fringed with hairs and tuba analis without scaphium.........................................

2. Tegumen large, broad, well-formed and slightly sclerotized......A. biconicaKolar

Both tegumen and uncus are almost identical in length, both arms tegumen wide, inverted V-shaped and weakly sclerotized.............................. 4

3. Juxta shield-like has highly-sclerotized transtilla. Sacculus round and has triangular shape projection ................................................ sicca Guenee

Juxta and transtilla are membranous. Sacculus round and has a spine-like projection....5

4. Vesica of the aedeagus is membranous, partly scobinate by single and large cornutus while laterally ingoing ductusejaculatorious......A. plecta Linnaeus

- Vesica is membranous, incompletely scobinate without cornuti with sub apically entering ductusejaculatorious..................................6

5. Valva symmetrical, well-developed and divided into parts. Costal area long and arm like............................ putris Linnaeus

- Valva is spatulate and elongated. Clavus fine and almost straight in length..............7 
6. Uncus is narrow and straight, juxta shield-like and almost round shape....A. rachingeri Gyulai and Saldaitis

- Uncus is apically straight broader, juxta of the genitalia just look like a flower and slightly hooked

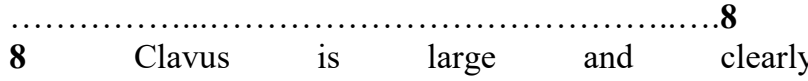
visible.................... kinabaluensisHolloway

- Clavus is short and
inconspicuous..................................9

9 Vesica of aedeagus has single dentate ridge.......... infusa (Boisduval)

Vesica of the genital aedeagus has numerous dentate ridges..........................10

10 Tip of the clasper is pointed........... colossa Gyulai and Saldaitis

- Clasper is curved and round shape apically................................11

11 In the case of female genitalia, both bursa seminalis and bursa copulatrix are equal in diameter........................... munda Walker

- $\quad$ The diameter of the bursa seminalis is thicker than bursa copulatrix.................12

12 Valva of the male genitalia is wide at distal margin while in female genitalia, ostiumbursi is shallow, round and cup-shape..............A. radians Guenee

Valva is distally short in length. Ostium is small, round and cup shape..................13

13 Female genitalia, signum is weakly sclerotized and has scobinate patches..........A. cygnea Common

- Ductus copulatrix has a thick and oval shape signum................................14

14 Corona has a series of well-developed marginal spines and clavus is short........A. interjectionis Guenee

- Corona has a sequence of slightly tapering spines and clavus is moderate in size........15

15 Clasper of the valva curved and slightly round apex.......A. poliophaea Turner

- Clasper $\quad$ stout-shape $\quad$ with
apex $\ldots \ldots \ldots \ldots \ldots \ldots \ldots \ldots \ldots \ldots \ldots \ldots \ldots \ldots \ldots \ldots \ldots \ldots \ldots$

16 In male genitalia, vescia has 2 dentate patches............... poliotisHampson

- Dentate patches absent on vescia of the aedeagus...................................17

17 Tegumen without scaphium ...A. porphyricollis Guenee

- $\quad$ Tegumen has well-developed scaphium ...18

18 Valva is leaf-like and penicular hairs absent.............. benigna Corti

- Valva is leaf-like fringed bypenicular hairs...19

19. Tubular shape aedeagus that has thorn-shape thical appendage. Membranous and long conjunctival lobe, at the base it has proximally large spine shape structure and group of small spines. At inner and median margins of vesica have small ring-like cornuti............................ oblique Smith
Aedeagus of the genital organ cylindrical that sinuated at distal margin of theca, approximately 100 membranous conjunctival lobes are large and its distal margin has membranous leaf-like processes. Cornuti found at the base of the aedeagus.............20

20. Tegumen, scaphiumand harps on the valva are lager in length......A. malefida Guenee

Tegumen lack the scaphium and harps are shorter in length..........................21

21. Uncus is long, curve from the base and hairy. Vinculum $\mathrm{u}$-shaped.............. ipsilon (Hufnagel)

- Uncus is elongate, curve nearly from the base and hairs absent. Vinculum v-shape ...A. hirsutumus Sp. Nov 22. Dorsal edge of clasper is straight and smooth. Both costal and ventral borders of the valva are curved................. beesoni Kapur and Aurora

Ventral and costal margin of the valvais straight and clasper is slightly sharp............23

23. The wingspan of the adult is around 33-41 $\mathrm{mm}$ in length, forewing light brown to gray in color...................... psammocharisBoursin

- $\quad$ Adult wingspan is about 29-33 $\mathrm{mm}$ in length, usually, forewings are garish brown.................................24

24. In female genitalia ovipositor is small, both ductus and corpus bursi are short but equal in length.......................... lasserrei Oberthur

Ovipositor of the female genitalia is long and ductus bursi is larger than corpus bursi....25

25. Antennae are intensely pectinate, light brown to light gray color forewings. light brown to light gray.................................. obesascytha Alpheraky

Simply pectinate antennae. Forewings are light brown to creamy color.................26

26. Distal $1 / 3^{\text {rd }}$ area of the valva is narrow, round apex. Clasper is short and sickle-like clasper .............. A. bifurcagrossi Hacker and Kuhna

Costal edge of the valva is moderately arched. Clasper is long and sickle-shape. 27

27. In the female copulatory organ, appendix bursaeare long, curve, cylinder-shape and two times larger than corpus bursae........A. bigramma Esper

Appendix and corpus bursi of female genitalia are long, tube-like and curve. Occasionally appendix bursi either long or almost identical in length to the corpus bursi ..............................................28

28. Valve are reasonable in size, its costal area is nearly straight and ventral area arched .......................... spiniferaHübner

Valva islong; the distal $1 / 3^{\text {rd }}$ area is comparatively narrow, sharp. Its costal and ventral parts are curved................................29

29. Clasper is moderate in size and round about slender like.....A. herzogi Rebel

Clasper is sickle typ 30 
30. The wingspan of the adult is $28-32 \mathrm{~mm}$ in size, whitish creamy forewing. A. puta Hübner

- Adult wingspan is $34-42 \mathrm{~mm}$, forewings are gray to brown color.......................31

31. Posterior apophyses of the female genitalia are larger than anterior apophyses and appendix bursae 2 times as long as the corpus bursae........A. sardzeana Brandt

In female genitalia, posterior apophyses are almost the same in size as anterior apophyses. Appendix bursae 3 times as long as corpus bursae................................................32

32. Ductusbursaeare short, narrow at distal half of the portion with highly sclerotized bands .................................... exclamationis (Linnaeus)

- Ductus burase long in size. Ostiumburase well sclerotized.................................33

33. Aedeagus is broad at the center, tube shape. Vesica is 4 times longer than the aedeagus.....34

- $\quad$ Aedeagus is wide at the medial. Vesica 5 times longer than the aedeagus.......... A. trux Hübner

34. The sub-terminal line of the forewing is prominent and dark brown in color. Hind wings are a pearl to white color.......A. segetum (Denis and Schiffermüller)

The sub-terminal line of the forewing is obsolescent. Hind wings are light cream color mixed with light gray color.........35

35. Antennae are pectinate but distally reduced this feature. .... A. clavis (Hufnagel)

- $\quad$ The antenna is bi-pectinate and gently tapered towards the apex...............36

36. Vesica 6 times as long as aedeagus having 1 and $1 / 2$ wide loops, sub-triangular shape right basal diverticulum is present..........A. propriens Dayar

- Vesica 2 times as long as aedeagus, 1 and 1/2 wide loops without right basal diverticulum.....37

37. Patagium is slightly darker than thorax with the black medial line. Tegulum is lighter in color than thorax with black basal line. A. steniptera Dognin

Patagium of the thorax have black medial line, apex half of the thorax is slightly lighter than thorax and tegulum without basal line.................38

38. Ampulla 1/4 time as long as the valva, half of the base is long and narrow to its $1 / 2$ wide diameter ...A. bistrigata Maassen

- $\quad$ Ampulla 1/5 time as long as the valva, basal 1/3 is elongated and narrow to its $1 / 3$ wide diameter.....A. dispar Köhler

Agrotis hirsutumus Sp. Nov

\section{Description}

Head: Head and vertex of the body are concealed by brown hairy scales. Antennae bipectinate and inverted labial palpi. Golden brown eyes. Thorax: Thoracic area enclosed with smoky brown scale, forewing ground with pale brown color while costal area is brown. Antemedial, postmedial and subbasal lines of the fore wings have pale area extended up to the post medial and sub marginal lines. Hind wings are the white color with brown costa. Outermost half veins and terminal line of the hind wing are brown. Abdomen: Abdominal segment of the body is hairy and fringed by brown scales (Fig. 2A).

\section{Type Species}

Holotype: ô, 9.x.2017 Yazman, (M. Sajjad) District Bahawalpur, Punjab Pakistan deposited in taxonomic laboratory.

Paratype: Punjab: Bahawalpur: Yazman 03§, 9.x.2017,

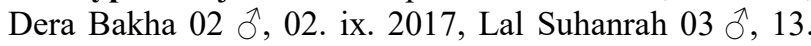
ix. 2017, Khanqah Sharif 03ð̄, 17.x. 2017, Chak No. 7BC $03 \hat{\jmath}, 21$. x. 2018.

Etymology: The specific name hirsutumusis derived from its host crop cotton (Gossypium hirsutum)

Male genitalia characters of Agrotis hirsutumus Sp. Nov: Tegumen is long, broad, well developed and highly sclerotized. Valva is elongated and fully formed, but thin near the base and become wide apically. Valva also looks just like a leaf with long, robust and spine like harps. Sacculus highly sclerotized. Costal margin of the valva is concave and somewhat hairy while ventral margin straightforward up to center and then curved. Flower-like juxta with a pointed base. Vinculum u-shaped and short highly sclerotized saccus with pointed base (Figure 2D). Aedeagus of male genitalia is stout shape, vesica coiled with small numbers of cornuti and its central area dark and thick. (Figure 2E).

Table 1. Measurement of different morphological and genital parts (mm) of $A$. hirsutumus Sp. Nov.

\begin{tabular}{cc}
\hline Characters & A. hirsutumus Sp. Nov. \\
\hline Head & 4 \\
Antennae & 7 \\
Wingspan & 25 \\
Aedeagus & 3.5 \\
Valva & 4 \\
Saccus & 0.8 \\
Tegumen & 2.2 \\
Uncus & 1.0 \\
Juxta & 1.0 \\
Scaphium & 1.4 \\
Harp & 1.2 \\
\hline
\end{tabular}

Remarks on basis of the morphological characteristics: This species is closely resembled to already described species i.e., Agrotis ipsilon. In current collection, A. ipsilon was also examined both species were almost similar but $A$. hirsutumus Sp. Nov. differ 
from $A$. ipsilon. by the following characteristics. Head and vertex of $A$. ipsilon fringed with greyish hairs while in case of $A$. hirsutumus fringed with brown hairs. (ii) Eye color is black in $A$. ipsilon but golden brown in $A$. hirsutumus. (iii) Thorax region of $A$. ipsilon is covered with light grey scales while $A$. hirsutumus shielded with smoky brown scales. (iv) Wingspan of $A$. ipsilon is 43 $\mathrm{mm}$ while wingspan of A. hirsutumus is $25 \mathrm{~mm}$. (v) Forewings of the $A$. ipsilon are the pale grey color with black costal margin while in case of $A$. hirsutumus forewings are pale brown with the browncostal area. (vi) In $A$. ipsilon, sub-basal, antemedial and post medial lines are present on forewings with the black spot but in $A$. hirsutumussub basal, antemedial and post medial lines have pale brown spot. (vii) Hind wings of the $A$. ipsilon are semi-hyaline white and transparent but in $A$. hirsutumus hind wings are yellowish white in color.
Remarks on the basis of Physiological characteristics: This species also differ from $A$. ipsilon on base of reproductive system(i) Uncus of $A$. ipsilon is fringed by penicular hairs while lacking in case of $A$. hirsutumus $\mathrm{Sp}$. Nov. (ii) Tegumen of $A$. ipsilon is thinbut long and broad in $A$. hirsutumus. (iii) Uncus base of $A$. ipsilon has circlelike structure while in case of $A$. hirsutumus absent the ring like structure at uncus base. (iv) Aedeagus of $A$. ipsilon has maximum numbers of cornuti but in case of $A$. hirsutumus, aedeagus has minimum numbers of cornuti. (v) Uncus of $A$. ipsilon is slim, straight and short in length with pointed tip but in $A$. hirsutumus uncus is broad and curved with rounded tip. (vi) Harps short in length in $A$. ipsilon but in $A$. hirsutumus almost long in length.

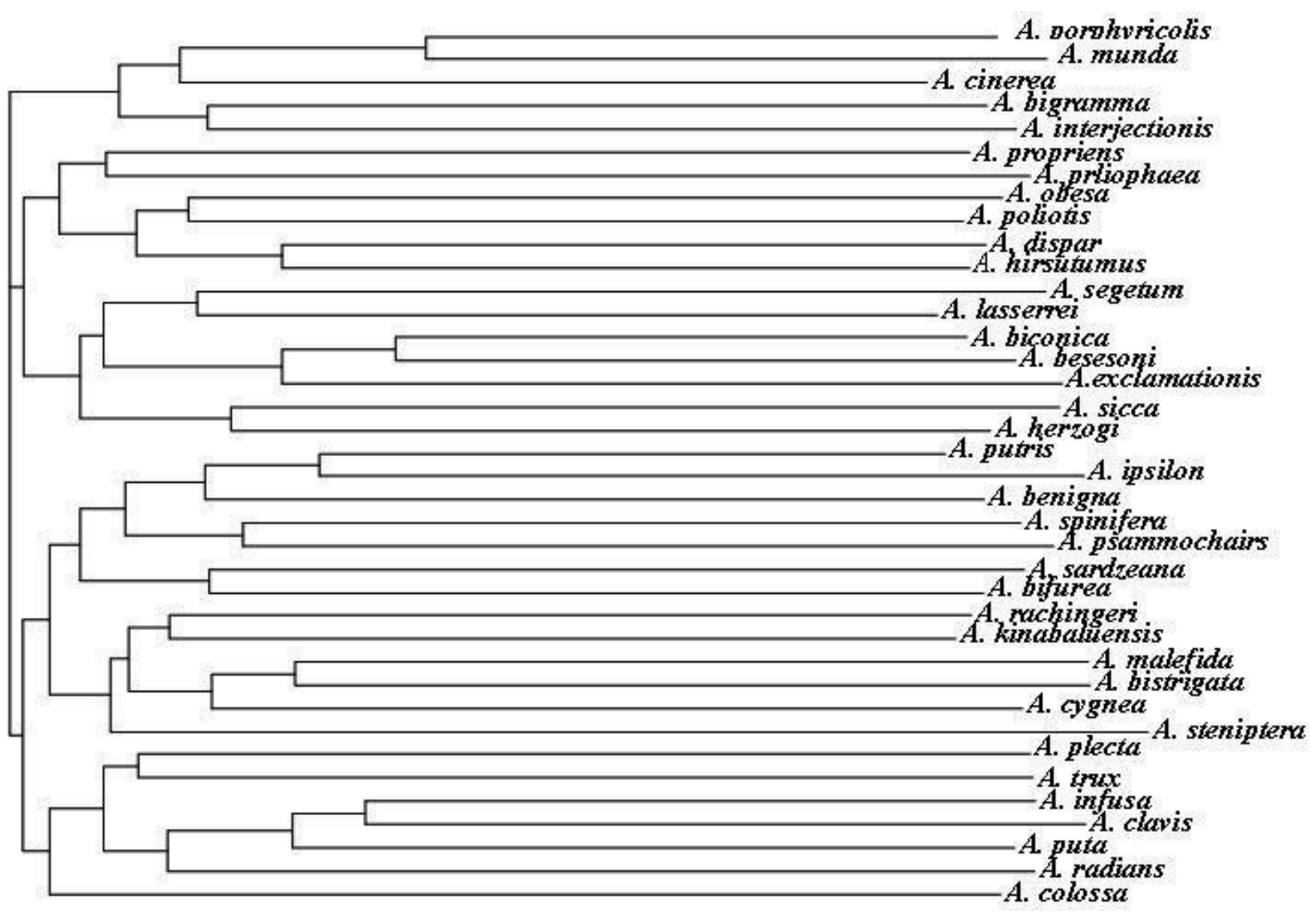

Figure 1. Dendrogram of different species of genus AgroDescription of Dendrogram.

Tegumen: Short and broad was found in Agrotis. cinerea, A. ipsilon, A. colossa, A. rachingeri, A. spinifera, A. clavis and $A$. benigna species. Tegumen is long and broad in A. biconica, A. sicca, A. plecta, A. kinabaluensis, A. putris, A. infusa, A. hirsutumus, A. psammochairs, A. obesa, A. bifurea, A. bigramma, A. sardzeana, A. exclamations, $A$. propriens, $A$. bistrigataand $A$. dispar. Narrow and short tegumen was found in A. munda, $A$. radians, A. cygnea, A. prliophaea, A. interjectionis, $A$. poliotis, A. porphyricolis, A. lasserrei, A. herzogi and $A$. puta while, narrow and long tegumen was present in $A$. besesoni, $A$. obliqua, $A$. trux, $A$. segetumand $A$. steniptera. Tegumen of the $A$. malefida is long, narrow and highly coved with penicular hairs. 
Uncus: Short and curved without penicular hairs were observed in Agrotis. cinerea, A. colossa, A. rachingeri and $A$. bistrigata while in some species uncus has short and curved that fringed with penicular hairs including $A$. munda, A. radians, A. cygnea, A. prliophaea, $A$. interjectionis, $A$. poliotis, $A$. porphyricolis and $A$. lasserrei. Uncus long, broad and curved without penicular hairs were found in A. ipsilon, A. sicca, $A$. plecta, A. putris, A. hirsutumus, A. besesoni, A. obesa, A. bifurea, A. spinifera, A. sardzeana, A. exclamations, A. segetum, A. trux, A. propriens, A. steniptera and A. dispar. Uncus long, broad and curve that covered with penicular hairs were present in A. infusa, A. obliqua, A. bigramma, A. herzogi,A. kinabaluensis, A. puta, A. malefida and A. clavis. In A. psammochairs, uncus was short and straight without penicular hairs on the other hand in A. benigna, uncus was short, straight that clothed with hairs. A. biconica, uncus long and straight that fringed with penicular hairs.

Valva: Elongate and cover with compact hairs in several species of Agrotis such as A. cinerea, A. ipsilon, A. biconica, A. puta, A. colossa, A. obliqua, A. rachingeri, A. infusa, A. hirsutumus, A. besesoni, A. malefida, A. psammochairs, A. herzogi, A. obesa, A. bifurea, A. spinifera, A. sardzeana, A. exclamations, A. trux, A. segetum, A. clavis, A. benigna, A. propriens, $A$. steniptera, A. bistrigata and A. dispar while in other species i.e., A. sicca, A. plecta, A. putris, A. munda, A. radians, A. cygnea, A. prliophaea, A. interjectionis, A. poliotis, A. porphyricolis, A. lasserrei and A. bigramma that have elongated and non-hairy valva. Valva leaf-like and non-hairy in A. kinabaluensis.

Juxta: In different species juxta pointed at the base in Agrotis. cinerea, A. obliqua, A. ipsilon and A. lasserrei. Juxta is flower like and membranous in A. puta, $A$. biconica, A. malefida, A. plecta, A. colossa, A. rachingeri, A. hirsutumus, $A$. psammochairs, $A$. obesa, $A$. bifurea, A. kinabaluensis, A. bigramma, A. spinifera, A. sardzeana, A. exclamations, A. trux, A. segetumA. clavis, A. herzogi, A. benigna, A. propriens, A. steniptera, A. bistrigata and $A$. dispar. Some species have shield-like juxta such as $A$ sicca, $A$. putris, $A$. infusa, A. radians, $A$. cygnea, A. prliophaea, A. interjectionis, A. poliotis and $A$. porphyricolis, while in other species including $A$. munda and $A$. besesoni that have triangular shape juxta.

Scaphium: Usually most of the species have well developed scaphium including: Agrotis. cinerea, $A$. obesa, A. bigramma, A. spinifera, A. herzogi, A. obliqua, A. puta, A. sardzeana, A. kinabaluensis, A. exclamations, A. trux, A. segetum, A. malefida, A. clavis, A. benigna, A. propriens and $A$. dispar. Other species like $A$. ipsilon, $A$. biconica, A. sicca, A. plecta, A. putris, A. colossa, A. rachingeri, A. infusa, A. munda, A. hirsutumus, $A$. radians, A. cygnea, A. prliophaea, A. interjectionis, A. poliotis, A. porphyricolis, A. besesoni, A. psammochairs, A. lasserrei, A. bifurea, A. steniptera and A. bistrigata in which scaphium absent.

Harp: Harp short in Agrotis. ipsilon, A. biconica, A. sicca, A. plecta, A. putris, A. obliqua, A. rachingeri, A. infusa, A. munda, A. kinabaluensis, A. radians, A. cygnea, A. prliophaea, A. interjectionis, A. poliotis, A. herzogi, A. porphyricolis, A. bifurea, A. spinifera, A. lasserrei, A. puta, A. exclamations, A. trux, A. segetum, A. clavis, A. benigna, A. propriens, A. steniptera, A. bistrigata,A. sardzeana, and $A$. dispar. While in other species that have the long HRP including $A$. cinerea, $A$. malefida, A. colossa, A. hirsutumus, A. besesoni, A. psammochairs, A. obesaandA. bigramma.

Vinculum and saccus: Both vinculum and saccus are long with pointed tip of the saccus in Agrotis. cinerea, A. malefida and $A$. infusa. Another species have both vinculum and saccus are short with rounded base saccus such as $A$. biconica, A. sicca, A. munda, A. radians, $A$. cygnea, A. prliophaea, A. interjectionis, A. poliotis, A. porphyricolis, A. besesoni, A. psammochairs, $A$. lasserrei, A. obesa, A. exclamations, A. clavis, A. benigna, A.rachingeri, A. steniptera, A. kinabaluensis, A. bistrigata and $A$. dispar. Some species i.e., A. bifurea, $A$. plectaand $A$. putris that have long vinculum and short saccus with rounded base. Vinculum short and saccus short with pointed base located in A. herzogi, A. ipsilon, A. colossa, A. hirsutumus, A. bigramma, A. spinifera, A. sardzeana, A. trux, A. segetum, A. puta, A. propriens and A. obliqua.

Aedeagus: In male genitalia, short and tube aedeagus found in most of the species including Agrotis. ipsilon, $A$. biconica, A. sicca, A. plecta, A. putris, A. rachingeri, A. infusa, A. munda, A. radians, A. cygnea, A. prliophaea, A. herzogi, A. interjectionis, A. poliotis, A. porphyricolis, A. besesoni, A. sardzeana, A. psammochairs, A. lasserrei, A. obesa, A. bifurea, A. bigramma, A. spinifera, A. puta, A. exclamations, A. trux, A. segetum, A. clavis, A. benigna, A. propriens, A. steniptera, A. kinabaluensis, A. bistrigata and $A$. dispar. While other species have long and cylindrical aedeagus found in A. obliqua, $A$. malefida, A. cinerea, A. colossa and A. hirsutumus.

Vesica: Dense dark in color, broad and short in length with cornuti observed in Agrotis. cinerea, A. ipsilon, A. biconica, A. colossa, A. rachingeri and A. hirsutumus. But in A. kinabaluensis and A. benigna have vesica dense dark in color, broad and short in length without cornuti. Some species i.e., A. sicca and A. lasserrei have vesical membranous, narrow and differ in length without cornuti. On the other hand, most of the species such as $A$. plecta, A. putris, A. psammochairs, A. obesa, A. herzogi, A. bifurea, A. bigramma, A. spinifera, A. puta, A. exclamations, A. trux, A. segetum, A. clavis, A. propriens, A. obliqua, A. steniptera, A. sardzeana, A. malefida, A. 
bistrigata and $A$. dispar that have vesical membranous, narrow and differ in length with cornuti. Vesica of the $A$. infusa has dentate tip and also located the cornuti while other species including $A$. munda, A. radians, $A$. cygnea,
A. prliophaea, A. interjectionis and $A$. poliotis. In $A$. porphyricolis and $A$. besesoni have both dentate bars and cornuti absent.
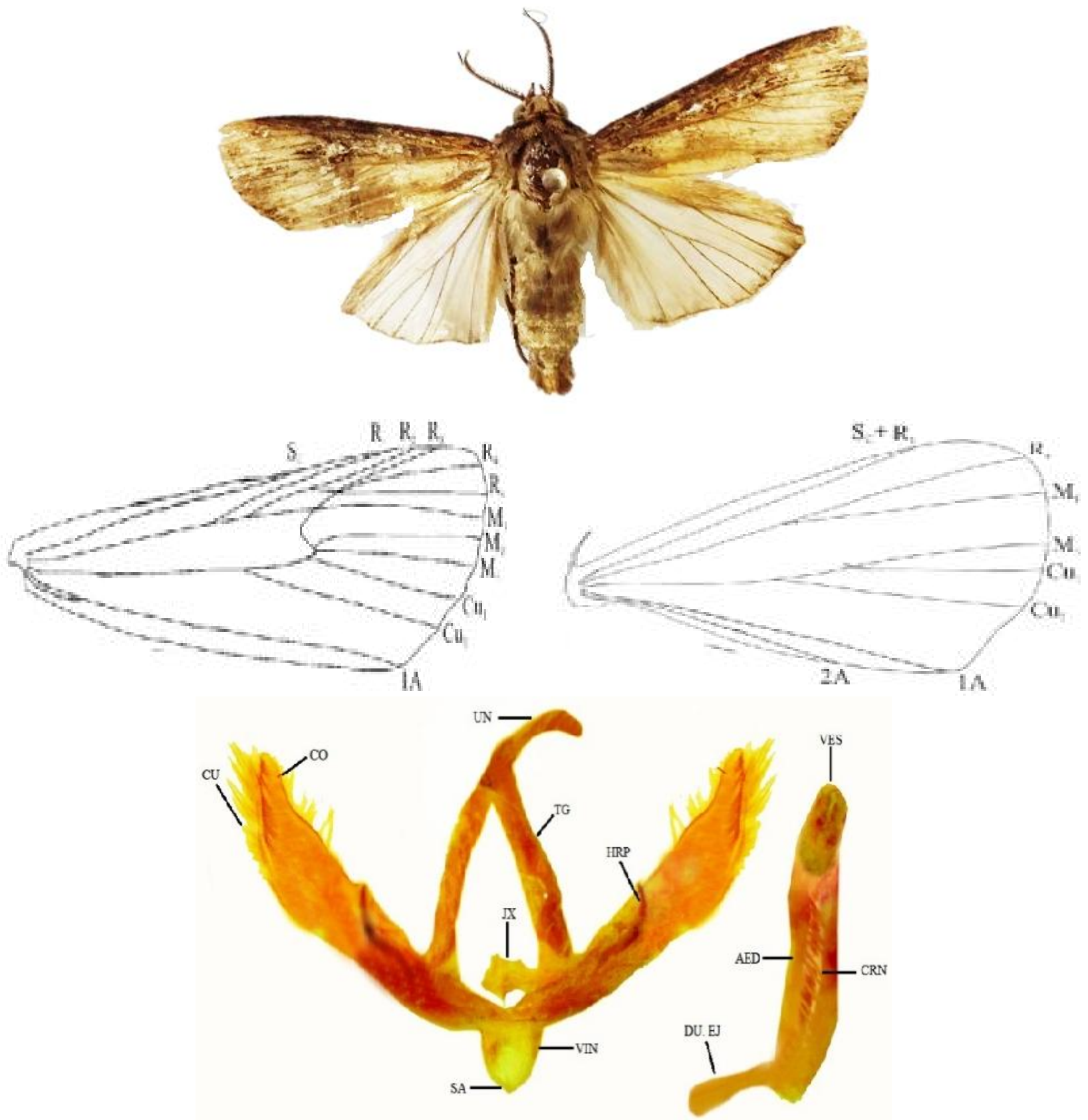

Figure2. Agrotis hirsutumus Sp. Nov. $\widehat{\delta}$ (A) adult dorsal view (B) Forewing (C) Hind wing (D) genitalia of (E) Aedeagus.

\section{REFERENCES}

Atay, E. (2012). The Genital Morphology and Major Taxonomic Characteristics of Zerynthiadeyrollei (Oberthür, 1869) and Zerynthiacerisyi (Godart,
1822) (Lepidoptera: Papilionidae: Zerynthiinae). Pakistan J. Zool. 44: 1343-1347.

Curtis, J. (1827). British Entomology, being illustrations and descriptions of the genera of insects found in Great Britain and Ireland; containing coloured 
figures from nature of the most rare and beautiful species, and in many instances of the plants upon which they are found in London.

Gillott, C. (2003). Male accessory gland secretions: modulators of female reproductive physiology and behavior. Annu. Rev. Entomol. 48: 163184.

Hampson, G.F. (1894). The Fauna of British India including Ceylon and Burma. Taylor and Francis Ltd., London. 1-609.

Hampson, G.F. (1920) On new genera and species of Lepidoptera Phalaenae, with the characters of two new families. Novit.Zoolog. 26: 253-282.

Hubner, J. (1821). Verzeichniss bekannter Schmettlinge, 1816-[1826]. Verz. bek. Schmett, 14: 209-224.

Jaroensutasinee, M., W. Pheera, R. Ninlaeard, K . Jaroensutasinee, and S. Choldumrongkul (2011). Weather affecting macro-moth diversity at Khao Nan National Park, Thailand. Walailak J. Sci. Tech.8: 21-31.

Kitching, I. J. (1984). An historical review of the higher classification of the Noctuidae (Lepidoptera). Bull. Br. Mus. Nat. Hist. Entomol. 4: 153-234.

Kravchenko, V., M. Fibiger, J. Mooser, and G. Muller (2006). The Noctuinae of Israel (Lepidoptera: Noctuidae). SHILAP Revta. Lepid. 34: 353-370.

Lafontaine, J. D. (2004). Noctuoidea: Noctuidae (part), Noctuinae (part-Agrotini). In: Hodges, R.W. (Ed.), The moths of North America, fascicle 27.1. Wedge Entomological Research Foundation, Washington, D.C. pp. 385.

Meena, A. K., R. Nagar, and R. Swaminathan (2017). Occurrence of genus Amyna (Noctuidae: Bagisarinae) among the semilooper complex infesting soybean at Udaipur. J. Entomol. Zool. Stud. 5: 949-953.

Nielsen, E.S. and I.F.B. Common (1991). Lepidoptera (moths and butterflies), In CSIRO Division of Entomology (ed.), The Insects of Australia. Melbourne: Melbourne University Press.817$915 \mathrm{pp}$.

Naz, S. (2011). Biodiversity and Faunastic Studies of the Sub-family Noctuinae (Lepidoptera: Noctuidae) from Pakistan with Cladistic Analysis. Deptt of
Zool. Fed. Urdu.Uni. Arts, Scie and Tech, Karch, pp. 337.

Ochsenheimer, F. (1816). Die, Schmetterlinge von Europa. Leipzig. Gerhard Fleischer. 1-224 pp

Pogue, M.G. (2006). The Noctuinae (Lepidoptera: Noctuidae) of Great Smoky Mountains National Park U.S.A. Zootax. 1215: 1-95.

Rabieh, M. M. (2018). Biodiversity of noctuid moths (Lepidoptera: Noctuidae) in the agro ecosystems of Mashhad County. Biodiv. Int. J. 2(2): 147-151.

Smith, J. B. (1890). Contribution toward a monograph of the insects of the Lepidopterous family Noctuidae of temperate North America. Revision of the species of the genus Agrotis.Bull. U. S. Natl. Mus.38: 5-237.

Schmidt, B.C. and J. Roland (2006). Moth diversity in a fragmented habitat: importance of functional groups and landscape scale in the boreal forest. Ann. Entomol. Soc. Am. 99:1110-1120.

Sekhon, C.K. and J. Singh (2015). Inventory of owlet moths from Western Ghats of India (Noctuidae: Lepidoptera). Int. J. Adv. Res. 1: 175-181.

Triplehorn, C. and N. Johnson (2005). Borror and DeLong's Introduction to the Study of Insects. 2005. Thomson Brooks/Cole, USA. 51-61 pp.

Van Nieukerken, E.J., L. Kaila, I. J. Kitching, N.P. Kristensen, D.C. Lees, J.Minet, C. Mitter, M. Mutanen, J.C. Regier, T.J.Simonsen, N. Wahlberg, S. Yen, R. Zahiri, D. Adamski, J. Baixeras, D. Bartsch, B. A. Bengtsson, J,W. Brown, S.R. Bucheli, D.R. Davis, J. de Prins, W. de Prins, M.E. Epstein, P. Gentili-Poole, C. Gielis, P. Hattenschwiler, A. Hausmann, J.D. Holloway, A. Kallies, O. Karsholt, A. Y. Kawahara, J. Koster, M. Kozlov, J.D. Lafontaine, G. Lamas, J. Landry, S. Lee, M. Nuss, K. Park, C. Penz, J. Rota, A. Schintlmeister, B .C. Schmidt, J. Sohn, M.A. Solis, G.M. Tarmann, A. D. Warren, S. Weller, R.V. Yakovlev, V.V. Zolotuhin, and A. Zwick (2011). Order Lepidoptera Linnaeus, 1758. In Zhang, Z.Q. (ed), Animal biodiversity: An outline of higher-level classification and survey of taxonomic richness. Zootax. 3148: 212-221. 